\title{
El derecho de voto de las personas con discapacidad y, en especial, de las personas con discapacidad psíquica o intelectual en derecho internacional. Su recepción en España
}

\author{
The right to vote of persons with disabilities and, specially, of persons \\ with mental and intellectual disabilities in public international law. \\ Its reception in Spain
}

\section{Resumen}

El presente estudio expone los diferentes tratados e instrumentos internacionales, de ámbito universal y regional, que protegen -directa $\mathrm{o}$ indirectamente- el derecho de participación política de las personas con discapacidad. En concreto, la Convención de Naciones Unidas sobre los Derechos de las Personas con Discapacidad (2006) supone un cambio de paradigma en el enfoque sobre la discapacidad, pues además de proclamar el derecho de participación política de todas las personas con discapacidad, reconoce su capacidad jurídica en igualdad de condiciones que el resto. La consecuencia de este análisis es que España debe garantizar el derecho de voto de todas las personas con discapacidad, con independencia del tipo de discapacidad (física, intelectual, psíquica o sensorial), siendo necesaria la adecuación de su legislación interna a las obligaciones internacionales contraídas, resultando por tanto obligatorio para las autoridades españolas la derogación o reforma del artículo 3 de la Ley Orgánica de Régimen Electoral General.

Palabras clave

Derecho al voto, participación política, personas con discapacidad, recepción, primacía del derecho internacional, igualdad y no discriminación.

\begin{abstract}
This study describes the different international treaties and instruments, at universal and regional levels, that protect -directly or indirectly- the right to political participation and the right to vote of all persons with all kind of disabilities. Specifically, the United Nations Convention on the Rights of Persons with Disabilities (2006) brings a change in the framework on disability, by proclaiming their right to political participation, and recognizing their legal capacity in equal conditions to the rest of the people. The consequence of this analysis is that Spain must guarantee the right to vote of all persons with disabilities regardless the type of disability (physical, intellectual, mental o sensory), being necessary the adaptation of its domestic laws to international engagements and obligations; therefore, the Spanish authorities are obliged to remove or reform of the article 3 of Electoral General Organic Law.
\end{abstract}

\section{Keywords}

Right to vote, political participation, persons with disabilities, reception, primacy of international law, equality and non discrimination.

\section{Víctor Carlos Pascual Planchuelo \\ <victorcp@ucm.es>}

Universidad Complutense de Madrid

\begin{abstract}
Para citar:
Pascual, V. C. (20I6): "El derecho de voto de las personas con discapacidad $\mathrm{y}$, en especial, de las personas con discapacidad psíquica o intelectual en derecho internacional. Su recepción en España”. Revista Española de Discapacidad, 4 (2): IOI-I22.
\end{abstract}

Doi: <https://doi.org/IO. 5569/23405 I04.04.02.06>

Fecha de recepción: 27-09-20I6 Fecha de aceptación: 28-II-20I6 


\section{Introducción}

El ejercicio de un derecho fundamental y tan básico como el derecho de voto sigue aun encontrando múltiples obstáculos, en muchos casos insalvables para las personas con discapacidad. La extensión de este derecho de naturaleza política a colectivos de personas originariamente privados de este derecho ha sido la causa y motor de numerosos movimientos sociales, revueltas, insurrecciones y revoluciones a lo largo de la Historia. En el siglo XXI, parece que esta fase de lucha social para conseguir el reconocimiento del derecho al voto se encuentra superada, por cuanto que el derecho a la participación política se encuentra ya plenamente reconocido prácticamente a todos/ as los/as ciudadanos/as en la inmensa mayoría de Estados que conforman la comunidad internacional actual.

Sin embargo, encontramos un colectivo, históricamente marginado, vulnerable y relegado de los asuntos públicos, que aún sigue sin ver reconocido en la mayoría de los Estados su derecho a la participación política y, en concreto, su derecho al voto: el colectivo de las personas con discapacidad y, en especial, el integrado por aquellas personas con discapacidad intelectual y psíquica.

El presente trabajo pretende poner de manifiesto que la exclusión del ejercicio del derecho de sufragio a una parte importante de la población de un país por el solo hecho de ser una persona con discapacidad (ya se trate de una discapacidad física, intelectual, psíquica o sensorial) no sólo va a constituir una práctica discriminatoria ilícita para con estas personas, sino que puede suponer una quiebra del ordenamiento jurídico internacional, que proclama y promueve los derechos humanos de todas las personas. Con tal fin examinaremos en los siguientes epígrafes las diversas normas y mecanismos legales y jurisdiccionales con los que cuenta el Derecho internacional público que proclaman y protegen el derecho de voto de las personas con discapacidad y, en concreto, de aquellas con discapacidad psíquica o intelectual ${ }^{\mathrm{I}}$.

Por último, dedicaremos un apartado específico al caso español para analizar en detalle los obstáculos legales que persisten en nuestro ordenamiento jurídico interno y que mantienen a una parte importante de la población, el colectivo de personas con discapacidad psíquica e intelectual, desprovistas del derecho a votar y elegir a sus representantes políticos en las elecciones.

\section{El derecho de voto de las personas con discapacidad en los tratados internacionales}

\subsection{El artículo 21 de la Declaración Universal de Derechos Humanos (1948)}

En el ámbito de los derechos políticos, la aprobación en 1948 de la Declaración Universal de los Derechos Humanos ${ }^{2}$ (DUDH) significó el inicio del desarrollo del derecho a la participación de toda persona en el gobierno de su país, aunque ello se hiciera mediante un texto no vinculante $a b$ initio jurídicamente, pero con un alto valor político y la fuerza positiva derivada de su obligatoriedad moral (Castro Rial, I998). El artículo 2 I de la Declaración Universal ${ }^{3}$ proclamó el derecho a

I. Deben diferenciarse ambos conceptos. Se define la "discapacidad intelectual" como aquel tipo de discapacidad que aparece antes de los I 8 años y que se caracteriza por limitaciones significativas tanto en funcionamiento intelectual como en conducta adaptativa tal y como se ha manifestado en habilidades adaptativas conceptuales, sociales y prácticas (Shalock et al., 20Io). Por su parte, el concepto de "discapacidad psíquica" nos remite al ámbito de la psiquiatría; en este terreno, las personas con discapacidad psíquica son aquellas que sufren trastornos que pueden dificultar o impedir el desarrollo de sus capacidades funcionales en relación a aspectos de la vida diaria como la higiene personal, autocuidado, autocontrol, relaciones interpersonales, interacciones sociales, aprendizaje, actividades recreativas y de ocio, trabajo, etc.; así como pueden dificultar la autosuficiencia económica (Goldman et al., I98 I:22). 2. Resolución Asamblea General, 2 I 7 A (III), el Io de diciembre de 1948 en París.

3. "Artículo $2 \mathrm{I}$

I. Toda persona tiene derecho a participar en el gobierno de su país, directamente o por medio de representantes libremente escogidos. 
la participación política como derecho humano (De La Rasilla, I998), que será la norma a la que se conecten y de la que surjan otros derechos humanos sustantivos.

Este artículo 2I recoge el derecho individual de "toda persona [...] a participar en el gobierno de su país”, participación que debe ser directa o a través de representantes libremente elegidos. El primer requisito del artículo 2I.3 es que deben realizarse elecciones para que el gobierno de turno fundamente su autoridad en la voluntad del pueblo, pero además se recogen otros elementos esenciales de ese derecho a la participación política, que incluye que se celebren elecciones periódicas, genuinas, mediante sufragio universal, sufragio igual y secreto de voto. El sufragio universal se refiere a quién tiene derecho a participar en las elecciones, debiendo entenderse de la forma más inclusiva posible (Comisión Europea, 2007:6).

Este cardinal -e innovador- artículo 2 I sería posteriormente desarrollado por el artículo 25 de un tratado internacional vinculante para los Estados, el Pacto Internacional de Derechos Civiles y Políticos, de 1966.

\subsection{El artículo 25 del Pacto Internacional de Derechos Civiles y Políticos (PIDCP) (1966): derecho de todos los ciudadanos a la participación política}

El artículo 25 del PIDCP estableció el "derecho de participación política de los individuos en las actividades de gobierno de los Estados ${ }^{4}$. El

2. Toda persona tiene el derecho de acceso, en condiciones de igualdad, a las funciones públicas de su país.

3. La voluntad del pueblo es la base de la autoridad del poder público; esta voluntad se expresará mediante elecciones auténticas que habrán de celebrarse periódicamente, por sufragio universal e igual y por voto secreto u otro procedimiento equivalente que garantice la libertad del voto."

4. "Artículo 25: Todos los ciudadanos gozarán, sin ninguna de las distinciones mencionadas en el artículo 2, y sin restricciones indebidas, de los siguientes derechos y oportunidades:

a) Participar en la dirección de los asuntos públicos, directamente o por medio de representantes libremente elegidos; artículo 25 PIDCP comienza con la expresión "todos los ciudadanos", lo que viene a concretar el contenido del artículo 2 I de la Declaración Universal (Boussuyt, I987). Ello significa que los Estados pueden limitar este concepto en base a sus criterios para definir quiénes son sus ciudadanos, sin que estos criterios puedan restringir indebidamente estos derechos de participación. En consecuencia con ello, el derecho de participación política quedará configurado en el ámbito internacional como un derecho "relativo" de aquellas personas que gozan de la condición de "ciudadanos" en los ordenamientos nacionales. El punto esencial será determinar cuándo una restricción a este derecho de participación política podrá considerarse adecuada o, por el contrario, "indebida", de acuerdo con la literalidad del citado artículo. Este rol interpretativo será llevado a cabo por el Comité de Derechos Humanos de la ONU, tal y como expondremos en el siguiente epígrafe.

Por otro lado, la vía por la cual los representantes serán elegidos para asegurar la libre expresión de la voluntad del pueblo se recoge en el apartado b) del artículo 25 del PIDCP, según el cual existirá el derecho y la oportunidad de
"votar y ser elegido en elecciones periódicas genuinas desarrolladas en base a sufragio universal e igual y celebradas con voto secreto, garantizando la libre expresión de la voluntad de los electores".

El artículo proclama el "sufragio universal de todos los ciudadanos", así como el "derecho de ser elegido”, que significa que todos los ciudadanos bajo el amparo de la Ley deberían tener no sólo el derecho sino también la opción de presentarse como candidatos, incluido el derecho a presentarse como candidatos independientes (Comisión Europea, 2007: I0).

b) Votar y ser elegidos en elecciones periódicas, auténticas, realizadas por sufragio universal e igual y por voto secreto que garantice la libre expresión de la voluntad de los electores;

c) Tener acceso, en condiciones generales de igualdad, a las funciones públicas de su país.” 
Este artículo 25 del PIDCP es un precepto básico de alcance universal, que establece la vigencia de una normativa electoral plenamente vinculante para los Estados que han ratificado el Pacto. Los países que han ratificado y, por tanto, se han obligado al cumplimiento del Pacto Internacional de Derechos Civiles y Políticos son, hasta la fecha, I68, una abrumadora mayoría de los Estados que componen la comunidad internacional. Se trata de una norma obligatoria para los Estados, que nos lleva a confirmar la existencia de un "derecho a la participación política para todos los ciudadanos" -sin restricciones indebidas- en derecho internacional público contemporáneo.

\subsection{El Comentario General número 25 del Comité de Derechos Humanos de la ONU sobre el artículo 25 del Pacto Internacional de Derechos Civiles y Políticos}

El Comité de Derechos Humanos desempeña la función vital de vigilar el disfrute de los derechos estipulados en el Pacto Internacional de Derechos Civiles y Políticos, y es el intérprete prominente de su significado y alcance. Entre sus numerosas y relevantes resoluciones, el Comité aprobó el Comentario General número 25: el derecho a participar en los asuntos públicos, el derecho de voto y el derecho de acceso igual al servicio público (I996), aportando elementos normativos extensos y clarificadores para la implementación del artículo 25 del PIDCP por parte de los Estados. En lo que guarda relación con el tema de este trabajo, este Comentario General enfatiza la necesidad de que las elecciones se lleven a cabo mediante sufragio universal y que las condiciones para el ejercicio de los derechos de participación política se basen en "criterios objetivos y razonables", es decir, que no caben "restricciones indebidas" al derecho de participación política.

En línea con ello, el Comentario General 25 enumera algunas de las restricciones y condiciones que las autoridades nacionales pueden establecer para acceder al derecho de sufragio. Así, los párrafos $3^{\circ}$ y $4^{\circ}$ disponen:
“3. [...] No se permite hacer distinción alguna entre los ciudadanos en lo concerniente al goce de esos derechos por motivos de raza, color, sexo, idioma, religión, opiniones políticas o de cualquier otra índole, origen nacional o social, posición económica, nacimiento o cualquier otra condición social [...].

4. Cualesquiera condiciones que se impongan al ejercicio de los derechos amparados por el artículo 25 deberán basarse en criterios objetivos y razonables. Por ejemplo, puede ser razonable exigir que, a fin de ser elegido o nombrado para determinados cargos, se tenga más edad que para ejercer el derecho de voto, que deben poder ejercerlo todos los ciudadanos adultos. El ejercicio de estos derechos por los ciudadanos no puede suspenderse ni negarse, salvo por los motivos previstos en la legislación y que sean razonables y objetivos. Por ejemplo, la incapacidad mental verificada puede ser motivo para negar a una persona el derecho a votar o a ocupar un cargo público.”

Según el tenor literal del Comentario transcrito, se acepta por el Comité como causa para privar del voto a una persona la "incapacidad mental verificada”. La consecuencia legal será inmediata: una gran parte, sino la mayoría, de las personas con discapacidad mental se verán impedidas legalmente para ejercer sus derechos de sufragio activo y pasivo por este motivo. El adjetivo "verificada" se entiende que requiere, al menos, de un análisis imparcial, exhaustivo e individualizado, mediante decisión judicial, por lo que el propio Comité, a pesar de fijar esta restricción como debida, ya parecería fijar ciertas garantías para la limitación de este derecho.

Asimismo, la labor interpretativa del Comité de Derechos Humanos, como receptor de las comunicaciones individuales y denuncias en base al Protocolo Facultativo del PIDCP, resulta fundamental para precisar las notas configuradoras del derecho a la participación política plasmado en el artículo 25. Algunas importantes resoluciones del Comité que han ido configurando este derecho de participación 
política son las dictadas en los casos Yong Joo Kang contra República de Corea, caso Gillot y otros contra Francias o en el caso Svetik contra Bielorrusia $^{6}$. En el marco de esta función, el Comité también ha interpretado en sus decisiones sobre comunicaciones individuales lo que debe entenderse por "restricciones indebidas” al derecho de participación. Ninguna de las resoluciones que analizan de forma pormenorizada este concepto aborda de forma exhaustiva los derechos de participación política de las personas con discapacidad, pero sin embargo sí aportan elementos interpretativos de interés y limitan la posibilidad de que los Estados restrinjan el derecho de voto de determinadas personas de manera indebida o injustificada.

\subsection{La Convención Internacional sobre los derechos de las personas con discapacidad (2006): el derecho a la participación política de las personas con discapacidad (artículo 29) y su relación con la capacidad jurídica (artículo 12)}

La interpretación restrictiva del artículo 25 del PIDCP efectuada por el Comité de Derechos Humanos, en lo que concierne a las personas con discapacidad, se vería superada por la aprobación en Nueva York en 2006 de la Convención sobre los derechos de las personas con discapacidad (CDPD). Esta Convención internacional ha supuesto un "cambio de paradigma” en la concepción de los derechos humanos de las personas con discapacidad: a partir de su entrada en vigor, las personas con discapacidad pasan a ser consideradas sujetos de derechos, con plena participación en la formulación y ejecución de los planes y políticas que les afectan (Sanjosé Gil, 2007a).

El alcance universal y el carácter tuitivo de esta Convención fueron destacados desde el inicio de las negociaciones y trabajos preparatorios del texto, habida cuenta que existía un elevado

5. Comité de Derechos Humanos. Gillot y otros contra Francia. Comunicación $n^{\circ}$ 932/2000, párrafo 13.7 .

6. Comité de Derechos Humanos. Comunicación N 927/2000. Svetik v. Belarús. consenso en que la Convención “debería proteger los derechos de todas las personas con discapacidad, independientemente de cuál fuera el tipo de discapacidad" (Sanjosé Gil, 2007b: I I 5); es decir, que la Convención no sólo proclama y protege los derechos de las personas con discapacidad física, motora o sensorial, sino que también incluye en su ámbito personal a las personas con discapacidad psíquica e intelectual, un amplio espectro de personas que aglutina muy variados tipos y modalidades de discapacidad (Organización Mundial de la Salud, 200I). De igual manera, en esta fase negociadora, debemos destacar el acuerdo en incluir en el texto final la frase "en pie de igualdad con las demás personas”, lo que venía a otorgar un papel esencial al "principio de no discriminación por motivos de discapacidad", sobre el que posteriormente abundaremos.

Este tratado internacional, ratificado por más de I60 países, aceptado de forma abrumadora por la comunidad internacional, proclama en su artículo 29 el "derecho de participación política de las personas con discapacidad en igualdad de condiciones que el resto de ciudadanos”. A fin de dar cumplimiento al derecho plasmado en el citado precepto, con el objeto de superar los obstáculos que pudieran existir al ejercicio de este derecho, el texto internacional obliga a los Estados a realizar "ajustes razonables 7 " en sus legislaciones y prácticas para garantizar y hacer efectivo el ejercicio de los derechos de participación política de las personas con discapacidad, derechos esenciales para empoderar y dar voz a las personas que tienen algún tipo de discapacidad física, sensorial, psíquica o intelectual ${ }^{8}$. En relación a este

7. El artículo 2 de la Convención define el concepto: "Por "ajustes razonables" se entenderán las modificaciones y adaptaciones necesarias y adecuadas que no impongan una carga desproporcionada o indebida, cuando se requieran en un caso particular, para garantizar a las personas con discapacidad el goce o ejercicio, en igualdad de condiciones con las demás, de todos los derechos humanos y libertades fundamentales." 8. "Artículo 29. Participación en la vida política y pública. Los Estados Partes garantizarán a las personas con discapacidad los derechos políticos y la posibilidad de gozar de ellos en igualdad de condiciones con las demás y se comprometerán a:

a) Asegurar que las personas con discapacidad puedan participar plena y efectivamente en la vida política y pública en igualdad de condiciones con las demás, directamente o 
derecho de participación política, el nuevo tratado no se limita a enunciar intenciones o principios inspiradores, sino que define de manera precisa derechos para las personas con discapacidad y obligaciones para los Estados.

De manera que, si desglosamos su contenido, podemos comprobar que el artículo 29 de la CDPD recoge y proclama los siguientes derechos políticos para las personas con discapacidad:

I. Derecho de voto en elecciones y referéndums; voto secreto, libre e igual.

2. Derecho a ser elegidas para ocupar cargos públicos.

3. Derecho de participación en organizaciones y asociaciones no gubernamentales.

4. Derecho a constituir organizaciones relacionadas con la vida pública y política.

5. Derecho a designar a una persona de su elección para que les preste asistencia para votar, si así lo solicitan.

Derechos que, a su vez, implican las siguientes obligaciones para los Estados que son Parte de la Convención: ${ }^{9}$

a través de representantes libremente elegidos, incluidos el derecho y la posibilidad de las personas con discapacidad a votar y ser elegidas, entre otras formas mediante: i) La garantía de que los procedimientos, instalaciones y materiales electorales sean adecuados, accesibles y fáciles de entender y utilizar; ii) La protección del derecho de las personas con discapacidad a emitir su voto en secreto en elecciones y referéndum públicos sin intimidación, $\mathrm{y}$ a presentarse efectivamente como candidatas en las elecciones, ejercer cargos y desempeñar cualquier función pública a todos los niveles de gobierno, facilitando el uso de nuevas tecnologías y tecnologías de apoyo cuando proceda; iii) La garantía de la libre expresión de la voluntad de las personas con discapacidad como electores y a este fin, cuando sea necesario y a petición de ellas, permitir que una persona de su elección les preste asistencia para votar;

b) Promover activamente un entorno en el que las personas con discapacidad puedan participar plena y efectivamente en la dirección de los asuntos públicos, sin discriminación y en igualdad de condiciones con las demás, y fomentar su participación en los asuntos públicos y, entre otras cosas: i) Su participación en organizaciones y asociaciones no gubernamentales relacionadas con la vida pública y política del país, incluidas las actividades y la administración de los partidos políticos; ii) La constitución de organizaciones de personas con discapacidad que representen a estas personas a nivel internacional, nacional, regional y local, y su incorporación a dichas organizaciones.”

9. La ratificación del Reino de España se produjo el 23 de noviembre de 2007 , y publicado en el BOE de 2 I de abril de
I) Los Estados deben garantizar el ejercicio efectivo de los derechos proclamados en la Convención.

2) Los Estados deben garantizar y asegurar el goce efectivo de estos derechos por las personas con discapacidad en igualdad de condiciones con las demás.

3) Los Estados deben garantizar que los procedimientos, instalaciones y materiales sean accesibles y de fácil comprensión para todas las personas con discapacidad.

4) Los Estados deben proteger el secreto del voto de las personas con discapacidad.

5) Los Estados deben facilitar el uso de nuevas tecnologías y tecnologías de apoyo cuando proceda para el ejercicio efectivo de los derechos de participación política de las personas con discapacidad.

6) Los Estados deben permitir a las personas con discapacidad que puedan designar a una persona para que les asista en el momento de ejercer su derecho al voto.

7) Los Estados deben promover las condiciones necesarias para que las personas con discapacidad puedan participar plena y efectivamente en los asuntos públicos.

8) Los Estados deben fomentar la participación de las personas con discapacidad en organizaciones y asociaciones no gubernamentales relacionadas con la vida pública y política del país.

9) Los Estados deben fomentar la constitución de organizaciones de personas con discapacidad y su incorporación a estas.

En definitiva, el artículo 29 de la CDPD proclama y establece de forma indubitada, en toda su amplitud, sin mención a ninguna limitación, condición o requisito previo, que "todas las personas con discapacidad, todas, tienen derecho al voto en elecciones y referendos en igualdad de condiciones que el resto de personas sin discapacidad".

2008 , lo que condujo a la entrada en vigor de este tratado internacional en nuestro país el 3 de mayo de 2008. 
En conexión con el artículo 29, el artículo I2 de la Convención ${ }^{\text {Io }}$ afirma que las personas con discapacidad tienen capacidad jurídica en igualdad de condiciones con las demás en todos los aspectos de la vida. El vínculo entre ambos preceptos es capital, habida cuenta que la mayoría de los ordenamientos nacionales restringen o suprimen el derecho de participación política a las personas con discapacidad por entender que carecen de capacidad jurídica o de obrar para ello. En muchos casos, es la privación de la capacidad jurídica -normalmente en forma de incapacitación- la que conlleva el impedimento de ejercer el derecho al voto (Bariffi, 20I 5). Ahora bien, con arreglo al artículo i 2, el reconocimiento de la capacidad jurídica a todas las personas con discapacidad, en conjunción con el artículo 29 de la CDPD, exige un nueva visión adaptada al paradigma naciente y al enfoque de derechos humanos que introduce la Convención de 2006, cuya consecuencia habría de ser la ampliación y extensión de este derecho de participación política a todas las personas con discapacidad, que tienen capacidad jurídica, y en igualdad de condiciones con las demás personas.

En consecuencia, comprobamos que la Convención se sitúa -y sitúa a los Estados parteen un paradigma de personalidad jurídica plena para las personas con discapacidad, indemne a toda forma de intervención restrictiva (Pérez Bueno, 2008: 65-66), superando el enfoque tradicionalmente manejado sobre la capacidad jurídica -el "modelo de sustitución en la toma de decisiones"- que implicaba diferenciar entre capacidad jurídica y capacidad de obrar y que perpetuaba figuras como la tutela, para adoptar un nuevo modelo, el "modelo de asistencia en la toma de decisiones”, que debe de garantizar

I0. Artículo I2: “I. Los Estados Partes reafirman que las personas con discapacidad tienen derecho en todas partes al reconocimiento de su personalidad jurídica. 2. Los Estados Partes reconocerán que las personas con discapacidad tienen capacidad jurídica en igualdad de condiciones con las demás en todos los aspectos de la vida. 3. Los Estados Partes adoptarán las medidas pertinentes para proporcionar acceso a las personas con discapacidad al apoyo que puedan necesitar en el ejercicio de su capacidad jurídica. 4. Los Estados Partes asegurarán que en todas las medidas relativas al ejercicio de la capacidad jurídica se proporcionen salvaguardias adecuadas y efectivas para impedir los abusos de conformidad con el derecho internacional en materia de derechos humanos. [...]” el derecho a la igualdad de las personas con discapacidad, tanto en lo que atañe a la capacidad jurídica como a la capacidad de obrar, y que debe traducirse en la búsqueda de una nueva figura jurídica, basada en medidas de apoyo para la toma de decisiones a las personas con discapacidad, en detrimento de las tradicionales medidas de sustitución (Instituto de Derechos Humanos Bartolomé de las Casas, 2008), con la finalidad de que "la completa capacidad [de las personas con discapacidad] sea una realidad efectiva" (Pérez Bueno, 2008: 65-66).

Por lo tanto, en primer lugar, podemos concluir que impedir el derecho de voto de las personas con discapacidad contravendría normas internacionales (artículo I 2 y artículo 29) que son obligatorias para los Estados que han ratificado la CDPD; y, segundo, el tratado internacional de 2006 no exige ninguna condición o requisito previo a las personas con discapacidad para poder ejercer su derecho de voto, pues la voluntad de los Estados signatarios de la Convención internacional, y de los propios Estados que la han ratificado -salvo las escasas reservas y declaraciones interpretativas formuladas sobre este artículo $^{\mathrm{II}}-$, tal y como quedó plasmado en el tratado, radica en que todas las personas con discapacidad sin distinción deben ver reconocido y salvaguardado su derecho al voto.

Por tanto, de acuerdo con el brocardo latino ubi lex non distinguit, nec non distinguere debemus (donde la ley no distingue, nosotros no debemos distinguir), no cabe prima facie otra interpretación que no sea la lógica y literal consistente en reconocer de forma categórica el ejercicio del derecho al voto para todas las personas con discapacidad y la obligación que recae sobre los Estados Partes de promover y facilitar su ejercicio efectivo. Además, la contradicción que pudiera existir entre el artículo 25 del PIDCP y el CG 25 con los artículos I 2 y 29 de la CDPD podría quedar resuelta en base a los dos criterios de prelación

II. Las únicas reservas y declaraciones interpretativas formuladas sobre el artículo 29 de la CDPD fueron las de Francia, Malta, Singapur y la República Islámica de Irán. 
de fuentes existentes en derecho internacional público: Ley posterior derogat priori y Lex specialis derogat legi generali.

\subsection{El derecho de participación política de las personas con discapacidad en los ordenamientos jurídicos regionales}

En el continente europeo, podemos afirmar que el derecho de participación política se encuadra dentro de los conceptos de democracia y sociedad democrática, que inspiran los propios fundamentos del Consejo de Europa. Aunque la Convención Europea sobre Derechos Humanos $y$ Libertades Fundamentales (I950) no regula expresamente el derecho de participación política, sin embargo, el artículo 3 de su Protocolo Adicional (I952) sí establece el "derecho a elecciones libres" (Jarillo, 20I2: I64-I65) con el compromiso de los Estados Partes de "organizar, a intervalos razonables, elecciones libres con escrutinio secreto, en condiciones que garanticen la libre expresión de la opinión del pueblo en la elección del cuerpo legislativo". Nada se dice en este escueto precepto sobre los derechos de participación política de las personas con discapacidad, ni siquiera se recoge la necesaria universalidad del sufragio; sin embargo, como analizaremos en el apartado 2, su desarrollo interpretativo se ha llevado a cabo con profusión y exhaustividad por el Tribunal Europeo de Derechos Humanos.

Por otro lado, en el ámbito de la Unión Europea, el reconocimiento de la ciudadanía comunitaria y las fórmulas de participación política establecidas para el nivel comunitario suponen un gran avance como criterio de legitimación (ascendente) del propio sistema comunitario. En línea con ello, las instituciones de la Unión entienden la participación política dentro del concepto amplio de democracia y lo tratan en estrecha conexión con el resto de los derechos humanos (Pérez Luño, 2003).

En la proyección ascendente del derecho, el artículo 6 del Tratado de la Unión Europea, en su versión consolidada, declara que:
“I. La Unión reconoce los derechos, libertades y principios enunciados en la Carta de los Derechos Fundamentales de la Unión Europea de 7 de diciembre de 2000 , tal como fue adaptada el I 2 de diciembre de 2007 en Estrasburgo, la cual tendrá el mismo valor jurídico que los Tratados.”

En línea con ello, podemos afirmar que entre los distintos derechos que se incluyen en el concepto de "ciudadanía de la Unión” en los tratados comunitarios, se encuentra el "derecho de participación política" tal como se contemplaba en el artículo I9 del Tratado de la Comunidad Europea (después del Tratado de Niza), referido a las elecciones municipales y al Parlamento Europeo (Jarillo, 2006: 46I), que ha quedado plasmado finalmente en los artículos 39 y 40 de la Carta de los Derechos Fundamentales de la Unión Europea, de 7 de Diciembre de 2000, como derechos políticos de los ciudadanos de la Unión, el derecho a ser elector y elegible en las elecciones al Parlamento Europeo y en elecciones municipales, por sufragio universal ${ }^{12}$.

Sin salir del continente europeo, la OSCE (Organismo Supervisor de las Contrataciones del Estado) aprobó varios documentos políticos que representaron la culminación de un largo proceso negociador que comenzó con la aprobación del Acta Final de Helsinki, de I975, y que recogen de manera detallada los derechos de participación política. De gran relevancia resulta el Documento de Copenhague de la Dimensión Humana de la OSCE, de I990, que establece las condiciones necesarias en un sistema político y electoral para que "la voluntad del pueblo sirva de base para

I2. "Artículo 39. Derecho a ser elector y elegible en las elecciones al Parlamento Europeo

I. Todo ciudadano de la Unión tiene derecho a ser elector y elegible en las elecciones al Parlamento Europeo en el Estado miembro en que resida, en las mismas condiciones que los nacionales de dicho Estado.

2. Los diputados del Parlamento Europeo serán elegidos por sufragio universal, libre, directo y secreto.

Artículo 40. Derecho a ser elector y elegible en las elecciones municipales

Todo ciudadano de la Unión tiene derecho a ser elector y elegible en las elecciones municipales del Estado miembro en que resida, en las mismas condiciones que los nacionales de dicho Estado.” 
la autoridad del Gobierno". En concreto, el apartado 7.3 de este Documento dispone que "los Estados participantes garantizarán el sufragio universal e igual a todos los ciudadanos adultos”.

En otros ámbitos regionales, como el americano, el derecho a la participación política ha quedado recogido en los tratados regionales más relevantes, como es el caso del artículo 23 de la Convención Americana sobre Derechos Humanos, ${ }^{13}$ que reproduce en gran parte el artículo 25 del PIDCP. A pesar de proclamar el sufragio universal y afirmar que "todos los ciudadanos" deben gozar de los derechos políticos que se relacionan, lo cierto es que el apartado 2 del artículo 23 de esta Convención establece la posibilidad de restringir estos derechos "por razones de capacidad civil o mental”, de manera que permite a los Estados americanos establecer medidas en su legislación nacional para constreñir o limitar el ejercicio del derecho de voto de las personas con discapacidad. A mi juicio, esta restricción contradice el precepto universal que proclama el derecho de voto de las personas con discapacidad (art. 29 CDPD), en aquellos Estados americanos que hayan ratificado la CDPD.

Existen además otros ámbitos regionales que han desarrollado una importante labor de promoción y protección de este derecho a la participación política (Hartmann, 2003), más centrados específicamente en garantizar el sufragio universal, aunque no mencionen directamente el derecho de las personas con discapacidad.

I3. "I. Todos los ciudadanos deben gozar de los siguientes derechos y oportunidades:

a) de participar en la dirección de los asuntos públicos, directamente o por medio de representantes libremente elegidos; b) de votar y ser elegidos en elecciones periódicas auténticas, realizadas por sufragio universal e igual y por voto secreto que garantice la libre expresión de la voluntad de los electores, y

c) de tener acceso, en condiciones generales de igualdad, a las funciones públicas de su país.

2. La ley puede reglamentar el ejercicio de los derechos y oportunidades a que se refiere el inciso anterior, exclusivamente por razones de edad, nacionalidad, residencia, idioma, instrucción, capacidad civil o mental, o condena, por juez competente, en proceso penal."
En África, el artículo I 3 de la Carta Africana sobre los derechos de los pueblos y de los ciudadanos (I98I) (Carta de Banjul) ${ }^{\mathrm{I}}$ garantiza los derechos de participación de "todos los ciudadanos", aunque lo remite a las disposiciones de las leyes nacionales. Aun cuando se omite cualquier referencia a los derechos de participación política de las personas con discapacidad, el artículo 2 de la Carta afirma que "todo individuo tendrá derecho al disfrute de los derechos y libertades reconocidos y garantizados en la presente Carta sin distinción de ningún tipo como raza, grupo étnico, color, sexo, lengua, religión, opinión política o de otra índole, origen social y nacional, fortuna, nacimiento u otro status.”, por lo que el texto se inserta dentro de las normas internacionales que no aceptan ningún tipo de discriminación en el disfrute de estos derechos y libertades "por cualquier estatus".

En Asia, la Declaración de Derechos Humanos de Kuala Lumpur (I993), aprobada en el marco de la Organización Interparlamentaria de la ASEAN (Asociación de Naciones del Sudeste Asiático) contempla algunos aspectos referidos a la participación política ${ }^{15}$, en consonancia con el artículo 25 del PIDCP (Brems, 200I).

Por último, en el mundo islámico, la Declaración Islámica Universal de Derechos Humanos o Declaración del Cairo sobre los derechos humanos en el Islam de la Organización de la Conferencia Islámica (I990) contempla el derecho de toda persona a participar en los asuntos públicos dentro del marco general de la Sharia (Jarillo, 2006: 507). En términos generales, el artículo I recoge la no discriminación en el disfrute de los derechos fundamentales ${ }^{\mathrm{I}}$.

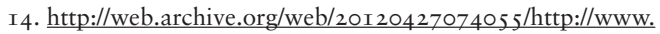
achpr.org/english/ info/charter en.html

I 5. Su artículo I5 dispone: "Todos los ciudadanos tienen derecho y deben tener la oportunidad, sin restricciones indebidas, a participar en la gestión de los asuntos públicos directa o indirectamente mediante representantes libremente elegidos, para votar y ser elegidos para el gobierno."

I6. "Todos los hombres son iguales en términos de dignidad humana básica y las obligaciones y responsabilidades básicas, sin discriminación alguna por motivos de raza, color, idioma, creencias, consideraciones de sexo, religión, afiliación política, condición social o de otra índole”. 
En definitiva, en el plano infraestatal, los convenios internacionales regionales refuerzan la obligatoriedad del derecho de participación política y, por ende, el derecho de voto de los ciudadanos y la universalidad del sufragio, sin restricciones indebidas, reafirmando y preconizando el principio de igualdad y no discriminación; en cuanto al derecho de voto de las personas con discapacidad no será sino hasta la aprobación de la Convención sobre los Derechos de las Personas con Discapacidad, cuando la conjunción del artículo 29 y I 2 de la CDPD empezará a poner en cuestionamiento, en algunos ámbitos regionales, especialmente el europeo, la viabilidad y procedencia de las restricciones al derecho de voto de las personas con discapacidad. Por lo tanto, debemos retornar a la vigencia de la CDPD y su unánime ratificación por la mayoría de países de la comunidad internacional, para recalcar que esta Convención convierte la participación política de las personas con discapacidad en un derecho exigible por los ciudadanos y obligatorio en la mayoría de Estados.

Para completar el análisis de este derecho de participación política en el ámbito del derecho internacional público, es preciso analizar a continuación la doctrina jurisprudencial que viene elaborándose por parte de dos tribunales internacionales de vital importancia en el terreno de los derechos humanos: el Tribunal Europeo de Derechos Humanos y la Corte Interamericana de Derechos Humanos.

\section{El derecho a la participación política de las personas con discapacidad en la jurisprudencia internacional}

\subsection{La Jurisprudencia del Tribunal Europeo de Derechos Humanos en materia de derechos de participación política de las personas con discapacidad}

En materia de derechos políticos, la Jurisprudencia del Tribunal Europeo de Derechos Humanos (TEDH) resulta esencial para entender el alcance y extensión del artículo
3 del Protocolo Adicional de la Convención Europea de Derechos Humanos. Reconociendo el carácter relativo del derecho a elecciones libres proclamado en el precitado artículo $3^{\mathrm{I7}}$, y admitiendo el margen de apreciación de los Estados para establecer restricciones legítimas al derecho de sufragio, la doctrina establecida por el Tribunal de Estrasburgo ha ido evolucionando hacia un mayor control y un estrechamiento de ese "margen de apreciación" ${ }^{18}$ estatal en la configuración legal de los requisitos para ejercer el derecho a elecciones libres (Sánchez Molina, 20I4: 37I-386), y ello con la finalidad de "mantener la integridad y efectividad de un procedimiento electoral encaminado a conocer la voluntad popular a través del sufragio universal" ${ }^{19}$.

Así, aunque el Tribunal reconoce que los Estados pueden establecer ciertos requisitos para el ejercicio de este derecho al sufragio en base a circunstancias políticas, sociales e históricas del país (por ejemplo, en materia de nacionalidad, residencia o duración mínima de ésta, inscripción en el censo, condena penal o discapacidad ${ }^{2 \circ}$ ), el Tribunal tiene capacidad para controlar que estas condiciones no lesionen la esencia del derecho de sufragio o su efectividad así como para impedir que estas restricciones sean arbitrarias (Pérez Alberdi, 2013: 346). En

I7. Vid. sentencia TEDH Mathieu-Mohin et Clerfayt c. Bélgica, Asunto 9/1985, de 28 de enero de I987, TEDH, pár. 52, que confirma que no se trata de un derecho absoluto: "Gozan los Estados en esta materia de un amplio margen de apreciación; pero corresponde al Tribunal resolver, en última instancia, sobre el cumplimiento de las exigencias del Protocolo núm. I". I8. La Doctrina del "Margin of appreciation" del TEDH consiste en otorgar un espacio de discrecionalidad a los Estados Partes para fijar el contenido y alcance de los derechos del Convenio Europeo para la Protección de los Derechos Humanos, tomando en consideración determinadas circunstancias jurídicas, sociales y culturales. Esta doctrina jurisprudencial se ha ido desarrollando por el Tribunal en numerosas sentencias, inter alia, Caso Matthews c. Reino Unido, Labita c. Italia, Aziz c. Chipre, Melnychenko c. Ucrania; también C-300/04 Eman y O.B. Sevinger / College van burgemeester en wethouders van Den Haag, etc.

I9. Vid. Sentencia STEDH de 30 de marzo de 2004 (asunto Hirst núm. 2 contra Reino Unido) y de 6 de octubre de 2005 (Gran Sala, Asunto Hirst contra Reino Unido).

20. Vid. inter alia DDCEDH de I I de diciembre de 1976 (asunto X contra Reino Unido), demanda $n^{\circ} 7566 / 76$ y de 2 I de mayo de 1997 (asunto Luksch contra Italia), demanda $\mathrm{n}^{\circ}$ 276I $4 / 95$. 
línea con ello, en su célebre Sentencia Hirst ${ }^{21}$, el Tribunal plasma un nuevo enfoque en relación al sufragio universal al enfatizar que "el derecho de voto no es un privilegio, y en el siglo XXI, la presunción en un Estado democrático debe obrar en favor de la concesión de este derecho al número más grande de personas”, lo que obviamente tendrá consecuencias en relación a las personas con discapacidad.

En este sentido, por ejemplo, en lo que respecta a los casos de privación del voto a los condenados y a las personas con problemas de salud mental o discapacidad intelectual, el Tribunal lleva a cabo un control más estricto, supervisando tanto la posible arbitrariedad de la medida como su proporcionalidad, con la finalidad de evitar la exclusión colectiva del derecho de sufragio de un grupo o categoría general de la población (Martínez- Pujalte, 20I 5 ).

En lo que respecta, en concreto, a los derechos de voto de las personas con discapacidad, la sentencia del TEDH en el Asunto Alajos Kiss contra Hungría ${ }^{22}$ devino trascendental. El Tribunal entendió contraria al artículo 3 del Protocolo de la Convención Europea de Derechos Humanos la privación automática del derecho de voto a todas las personas con algún tipo de desorden mental o intelectual, por considerarla desproporcionada, y exigió a las autoridades húngaras que esta medida debía ser excepcional -y no automática y general-, una vez realizada una evaluación individualizada de las capacidades de la persona con discapacidad, es decir, de su aptitud para el ejercicio del voto (Pérez Alberdi, 20I3: 350). Afirma el Tribunal:

“[...] Si una restricción de derechos fundamentales se aplica a un particular grupo vulnerable en la sociedad, que ha sufrido discriminación en el pasado, como las personas con discapacidad, entonces el margen de apreciación de los Estados se reduce

2I. Sentencia STEDH de 30 de marzo de 2004 (asunto Hirst núm. 2 contra Reino Unido) y de 6 de octubre de 2005 (Gran Sala, Asunto Hirst contra Reino Unido).

22. SSTEDH de 20 de mayo de 20 Io (Asunto Alajos Kiss contra Hungría). sustancialmente y deben existir razones de mucho peso para poder establecer restricciones a estos derechos (como el derecho a elecciones libres)".

En definitiva, con esta sentencia, el Tribunal viene a exigir una mayor argumentación y fundamentación para aceptar la privación del derecho de voto a personas con riesgo de exclusión social, como presos o personas con discapacidad ${ }^{23}$, lo que además debe ser la excepción y no la regla. A esta sentencia pionera le siguieron, entre otras, las sentencias Gajcsi contra Hungria, de 23 de septiembre de $2014^{24}$ y Harmati contra Hungría, de 2 I de octubre de $2014^{25}$, que consolidaron esta doctrina.

En suma, el TEDH establece una doctrina esencial para el desarrollo del derecho de participación política de las personas con discapacidad al calificar la privación del derecho de voto como una medida excepcional que sólo podrá adoptarse tras un examen individualizado. No obstante, comprobamos que el Tribunal no proscribe -aún- todas las restricciones al derecho de voto de las personas con discapacidad, lo que podría entenderse contradictorio con la literalidad del artículo 29 de la Convención de 2006. A pesar de ello, su gran virtualidad radica en que estrecha el cerco a tales restricciones y arrincona el margen de apreciación de los Estados, exigiendo a éstos que las restricciones a este derecho sean nítidamente razonables y proporcionales ${ }^{26}$, que persigan un fin legítimo ${ }^{27}$ y que eviten decisiones que pueden considerarse arbitrarias y contrarias a la libre expresión del pueblo ${ }^{28}$ y al principio fundamental de universalidad del sufragio.
23. Ibídem.

24. Sentencia del TEDH Caso GAJCSI v. HUNGARY (no. 62924/IO), de 23 de Septiembre de 2014. 25. Sentencia del TEDH Caso HARMATI v. HUNGARY (no. 630I2/IO), de 2 I de Octubre de 2014. 26. Vid. Hirst c. Reino Unido. 27. Sentencia TEDH Py c. Francia. 28. Sentencia TEDH Kavakçí c. Turquía. 
2.2. La Jurisprudencia de la Corte Interamericana de Derechos Humanos en materia de derechos de participación política de grupos y personas vulnerables

El continente americano cuenta con un fundamental tribunal internacional que vela por la protección y promoción de los derechos humanos contenidos en la Convención Americana de Derechos Humanos: la Corte Interamericana de Derechos Humanos (CIDH), con sede en San José, Costa Rica. En lo que concierne a la protección de los derechos políticos en el continente, la sentencia dictada el 23 de junio de 2005 por la CIDH en el Caso Yatama $^{29}$ significó un punto de inflexión. La Corte encontró que Nicaragua no adoptó las medidas necesarias para garantizar el goce del derecho a ser elegidos de los candidatos propuestos por la agrupación indígena Yatama, ya que se vieron afectados por la discriminación legal y de hecho, lo que impidió su participación en condiciones de igualdad en las elecciones.

La resolución de la Corte Interamericana sentenció que, al analizar el goce de estos derechos políticos, se debe tomar en consideración que se trata de personas que pertenecen a comunidades indígenas y étnicas, que se diferencian de la mayoría de la población por sus lenguas, costumbres y formas de organización, “y enfrentan serias dificultades que los mantienen en una situación de vulnerabilidad y marginalidad". Esta sentencia es de trascendental relevancia para el desarrollo de la jurisprudencia en materia de derecho internacional de derechos humanos (González Volio, 2005) y además resulta de gran importancia dado que es la primera vez que la Corte, en un caso contencioso, reconoce el carácter de ius cogens atribuido al "principio básico de igualdad y no discriminación”.

La sentencia Yatama ha creado una línea jurisprudencial, basada en la defensa del principio de la igualdad y la no discriminación en lo que respecta a las restricciones indebidas

29. Caso Yatama. Sentencia CIDH de 23 de junio de 2005. Serie C No. I 27. sobre el disfrute de derechos políticos, que ha marcado sucesivas resoluciones de la Corte $^{3^{\circ}}$. Asimismo, la doctrina jurisprudencial desarrollada en la Sentencia Yatama constituye un precedente fundamental para otras resoluciones posteriores dictadas por la Corte Interamericana de Derechos Humanos sobre derechos políticos, incluso no relacionados con pueblos indígenas ${ }^{31}$, en los que la que la Corte indicó que las condiciones y circunstancias generales que autorizan una restricción al ejercicio de un derecho humano deben estar claramente establecidas por una ley en sentido formal y material, al constituir el ejercicio efectivo de los derechos políticos un fin en sí mismo y, a la vez, un medio fundamental que las sociedades democráticas tienen para garantizar los demás derechos humanos (Dalla Via, 20II).

Por todo lo anteriormente expuesto, entendemos que esta línea jurisprudencial abierta con la sentencia Yatama, y reiterada en las resoluciones dictadas a posteriori, deja abierta la vía para que, llegado el caso, la Corte Interamericana de Derechos Humanos, en consonancia con los artículos recogidos en la Convención de Naciones Unidas sobre los Derechos de las Personas con Discapacidad de 2006, confirme y corrobore que las personas con discapacidad en el continente americano deben gozar de forma efectiva, y sin restricciones, del derecho de participación política sin discriminación y en igualdad de condiciones que las personas sin discapacidad.

30. Caso Escué Zapata Vs. Colombia. Sentencia CIDH de 4 de julio de 2007. (Fondo, Reparaciones y Costas), Caso del Pueblo Saramaka vs. Surinam. Sentencia CIDH de I 2 de agosto de 2008 (interpretación de la sentencia de excepciones, fondo, reparaciones y costas), Caso Chitay Nech y otros vs. Guatemala. Sentencia CIDH de 25 de mayo de 2010. (Excepciones Preliminares, Fondo, Reparaciones y Costas), Caso Pueblo Indígena Kichwa de Sarayaku vs. Ecuador. Fondo y reparaciones. Sentencia CIDH de 27 de junio de 20I2. Serie C No. 245 .

3I. Caso López Mendoza vs. Venezuela, Sentencia CIDH I de septiembre de 20II, Serie C No. 233; y Caso Castañeda Gutman vs. México. Excepciones Preliminares, Fondo, Reparaciones y Costas. Sentencia de 6 de agosto de 2008. Serie C No. I 84, párrs. 172. 


\section{El Comité de Naciones Unidas sobre los derechos de las personas con discapacidad y los derechos de participación política. EI examen a España}

Un panorama completo y comprehensivo del derecho de voto de las personas con discapacidad en el plano internacional obliga a abordar en este epígrafe el papel desarrollado por la instancia internacional que controla el cumplimiento de la Convención sobre los Derechos de las Personas con Discapacidad (CDPD), el Comité sobre los Derechos de las Personas con Discapacidad.

En primer lugar, debemos incidir en la relevancia de la Observación General elaborada por este Comité en fecha de 25 de noviembre de $2013^{32}$, que interpreta y desarrolla el concepto de "capacidad jurídica" aplicada a las personas con discapacidad y el derecho de participación política del artículo 29 CDPD. Al abordar el derecho de participación política, la Observación General dispone:

“[...] Para hacer plenamente efectivo el reconocimiento de la capacidad jurídica en igualdad de condiciones en todos los aspectos de la vida, es importante que se reconozca la capacidad jurídica de las personas con discapacidad en la vida pública y política (art. 29). Esto significa que la capacidad que tenga una persona de adoptar decisiones no puede justificar que se excluya a las personas con discapacidad de ejercer sus derechos políticos, incluidos el derecho de voto [...]. Los Estados tienen la obligación de proteger y promover el derecho de las personas con discapacidad a acceder al apoyo de su elección para emitir su voto en secreto y participar sin discriminación en todas las elecciones y referendos [...]".

Este enfoque se ha reafirmado de manera uniforme y constante en los diferentes informes

32. Observación General elaborada por el Comité sobre los Derechos de las Personas con Discapacidad, de 25 de noviembre de $2013\left(\mathrm{CRPD} / \mathrm{C} / \mathrm{II}_{4}\right.$ ). emitidos por el Comité en los exámenes del cumplimiento de la Convención que ha realizado a diversos Estados partes ${ }^{33}$. En lo que concierne al examen que el CDPD efectuó al Reino de España en $20 \mathrm{II}^{34}$, en relación al artículo 29 de la Convención, el Comité expresó su preocupación por la posibilidad de que se restringiera el derecho al voto de las personas con discapacidad intelectual o psicosocial en el caso de que la persona haya sido privada de su capacidad jurídica o internada en una institución, lo que además era la regla y no la excepción.

En este sentido, con el fin de que todas las personas con discapacidad tengan derecho a votar y puedan participar en la vida pública en pie de igualdad con los demás, el Comité de la ONU recomendó a las autoridades españolas que revisaran toda la legislación pertinente, y en concreto se pedía al Estado Español que modificara el artículo 3 de la Ley Orgánica 5/1985, de Régimen Electoral General:

“48. El Comité recomienda que se revise toda la legislación pertinente para que todas las personas con discapacidad, independientemente de su deficiencia, de su condición jurídica o de su lugar de residencia, tengan derecho a votar y a participar en la vida pública en pie de igualdad con los demás. El Comité pide al Estado parte que modifique el artículo 3 de la Ley orgánica $\mathrm{N}^{\circ}$ 5/1985, que autoriza a los jueces a denegar el derecho de voto en virtud de decisiones adoptadas en cada caso particular. La modificación debe hacer que todas las personas con discapacidad tengan derecho a votar ${ }^{3536 "}$.

33. Así, por ejemplo, en el examen a Túnez, el Comité recomendó a las autoridades tunecinas que “...se adopten con urgencia medidas legislativas para que las personas con discapacidad, incluidas las que están en régimen de tutela o curatela, puedan ejercer su derecho a voto y participar en la vida pública en pie de igualdad con las demás [...]".

34. Observaciones finales del Comité sobre los Derechos de las Personas con Discapacidad, Examen a España, I9 de octubre de 20II, Comité sobre los Derechos de las Personas con Discapacidad, Sexto período de sesiones, I9 a 23 de septiembre de 20 I I (CRPD/C/ESP/CO/I).

35. Vid. Recomendaciones 47 y 48 del informe de Observaciones Generales.

36. Similares observaciones se formularon por el Comité respecto de Argentina (CRPD/C/ARG/CO/I, I9 de octubre de 
Consecuencia de ello, se deduce fácilmente que España está obligada jurídicamente a garantizar que todas las personas con discapacidad (ya tengan una discapacidad física, psíquica, intelectual o sensorial, ya se encuentren institucionalizadas o no) puedan ejercitar de forma efectiva el derecho al voto y el derecho a presentarse como candidatos en las elecciones, debiendo adoptar las medidas necesarias para hacer efectivos estos derechos, facilitando -entre otras cuestiones- la accesibilidad, la información y la supresión de los obstáculos y barreras que aún subsisten para lograr el adecuado cumplimiento del artículo 29.

4. La recepción por parte de España de los artículos 29 y 12 de la Convención sobre los Derechos de las Personas con Discapacidad

Sentada la vigencia y exigibilidad del derecho de voto (y, en general, del derecho a la participación política) de las personas con discapacidad en el marco jurídico internacional, a continuación desde una óptica internacionalista queremos poner de relieve la primacía de las normas internacionales analizadas frente a las normas existentes en los diferentes ordenamientos jurídicos nacionales de los Estados, con objeto de evidenciar que la normativa interna de estos no puede erigirse en una barrera infranqueable para el correcto cumplimiento del derecho internacional.

Esta primacía del derecho internacional frente a los ordenamientos jurídicos internos deriva de convenios internacionales aceptados de forma cuasi unánime por los Estados, como el artículo 26 de la Convención de Viena sobre Derecho de los Tratados, de 23 de mayo de I969, que destaca el alcance del principio pacta sunt

20I2, párrafo 47), China (CRPD/C/HUN/CO/I, I 5 de octubre de 20I2, párrafo 45), Hungría (CRPD/C/HUN/CO/I, 22 de octubre de 20I2, párrafo 45), y Paraguay (CRPD/C/PRY/CO/I, I 5 de mayo de 2013 , párrafo 6I) servanda, es decir "todo tratado en vigor obliga a las partes y debe ser cumplido por ellas de buena fe".

Profundizando en ello, el artículo 27 del mismo texto legal lo refleja aún de forma más terminante: "Una Parte no podrá invocar las disposiciones de su derecho interno como justificación del incumplimiento de un tratado". De conformidad con esta norma convencional, la jurisprudencia de la Corte Internacional de Justicia y de los Tribunales arbitrales ha reflejado en numerosas resoluciones la primacía del derecho internacional sobre el derecho interno (Andrés Sáenz de Santamaría, 2014: 209). Así, en el asunto de las Comunidades greco-búlgaras, ${ }^{37}$ el Tribunal Permanente de Justicia Internacional concluyó:

"es un principio generalmente reconocido del Derecho de gentes que, en las relaciones entre las Potencias contratantes de un tratado, las disposiciones de una ley interna no pueden prevalecer sobre las del tratado ${ }^{38}$ ".

En consecuencia, en caso de incumplimiento de un tratado u otra norma internacional, en base a una norma interna, dicho Estado podría incurrir en responsabilidad internacional. No obstante, esta afirmación debe examinarse teniendo en cuenta el modo de recepción del derecho internacional público por parte de los Estados soberanos en su derecho interno. En el caso de España, la Constitución de I978 -en su artículo 96- consagra la primacía del derecho internacional sobre las normas internas:

"Los tratados internacionales válidamente celebrados, una vez publicados oficialmente en España, formarán parte del ordenamiento interno. Sus disposiciones sólo podrán ser derogadas, modificadas o suspendidas en la

\footnotetext{
37 Opinión Consultiva del CPJI, de 3 I de Julio de I930, asunto de las comunidades greco-búlgaras. 38 CPJI, Serie B, núm. I7, p. 32; CIJ, Recueil des Cours, Collected Courses of the Hague Academy of International Law, London, Martinus Nijhoff Publishers, I988, p. 35. Vid. inter alia la sentencia de la CPJI sobre el vapor "Wimbledon", de 28 de julio de I924, o el dictamen sobre las zonas francas de la Alta Saboya, de I930.
} 
forma prevista en los propios tratados o de acuerdo con las normas generales del derecho internacional".

En complemento a este precepto, el artículo 95 $\mathrm{CE}^{39}$ establece que los tratados tienen rango supralegal pero -a la vez- infraconstitucional. El legislador español, aun aceptando la primacía de los tratados sobre las normas internas, ha querido que la manifestación del consentimiento por parte del Gobierno en obligarse por un tratado esté supeditada a su previa conformidad con la Constitución, otorgando al Tribunal Constitucional la facultad de controlar la constitucionalidad de los tratados vigentes en España (Díez de Velasco, 20I3), o bien obligando al legislador a promover la reforma constitucional para la adecuación de nuestra Carta Magna al tratado internacional.

Por otro lado, la Constitución Española otorga a los tratados internacionales valor interpretativo en su artículo I0.2, permitiendo de esta forma la expansión de los derechos humanos proclamados en las convenciones internacionales y la aplicación de la jurisprudencia de la Corte Europea de Derechos Humanos en nuestro país (Cuenca Gómez, 2012).

En consecuencia, el reconocimiento en nuestra norma fundamental de la primacía de los tratados internacionales frente a las normas internas así como del valor interpretativo de la Declaración Universal de Derechos Humanos y de los tratados internacionales sobre derechos humanos que han sido ratificados por España, pone de manifiesto que ninguna norma contenida en nuestro ordenamiento jurídico interno puede contravenir una norma vinculante de derecho internacional público. En consecuencia con ello, en España, la Convención sobre los Derechos de las Personas con Discapacidad debe ser directamente aplicable por los poderes públicos y resulta plenamente exigible por los ciudadanos.

Esta premisa resulta fundamental para los fines

39. Art. 95 CE: "I. La celebración de un tratado internacional que contenga estipulaciones contrarias a la Constitución exigirá la previa revisión constitucional.” de nuestro trabajo. Desde un punto de vista técnico jurídico en las relaciones entre una ley anterior y un tratado posterior, la doctrina mayoritaria coincide en que un tratado posterior podrá derogar o modificar la ley anterior (Andrés Sáenz de Santamaría, 20I4: 223). De ahí que, a nuestro entender, la entrada en vigor en España de la Convención sobre los Derechos de las Personas con Discapacidad (2006) obliga al legislador español a reformar o derogar el artículo 3 de la Ley Orgánica del Régimen Electoral General (I985), habida cuenta que nuestro ordenamiento jurídico interno sigue sin dar un adecuado cumplimiento a los artículos 29 y I 2 de la Convención de Nueva York, en concreto, en lo que respecta al derecho de voto de las personas con discapacidad y, sobre todo, de las personas con discapacidad intelectual o psíquica.

Como hemos apuntado, en el ordenamiento jurídico español, el artículo 3 de la Ley Orgánica 5/I98 5, de I9 de junio, del Régimen Electoral General -que reproducimos-, recoge las causas de exclusión del derecho de sufragio:

"Artículo 3

I. Carecen de derecho de sufragio:[...]

b) Los declarados incapaces en virtud de sentencia judicial firme, siempre que la misma declare expresamente la incapacidad para el ejercicio del derecho de sufragio.

c) Los internados en un hospital psiquiátrico con autorización judicial, durante el período que dure su internamiento, siempre que en la autorización el Juez declare expresamente la incapacidad para el ejercicio del derecho de sufragio.

2. A los efectos previstos en este artículo, los Jueces o Tribunales que entiendan de los procedimientos de incapacitación o internamiento deberán pronunciarse expresamente sobre la incapacidad para el ejercicio del sufragio. En el supuesto de que ésta sea apreciada, lo comunicarán al Registro Civil para que se proceda a la anotación correspondiente".

Esta Ley, aprobada en los primeros años de la naciente democracia española, contenía una 
regulación no excesivamente restrictiva -para ese momento histórico- del derecho de voto de las personas con discapacidad, en base al requisito de la necesidad de una resolución judicial específica que declarara de forma expresa la incapacidad de las personas con discapacidad para el ejercicio del derecho de sufragio.

En los años posteriores, la regulación de los derechos de las personas con discapacidad en nuestro país experimentó un relevante desarrollo. Así, la Ley 51/2003, de 2 de diciembre, de igualdad de oportunidades, no discriminación y accesibilidad universal de las personas con discapacidad (LIONDAU) recogió la necesidad de regular los derechos políticos de las personas con discapacidad, motivo por el que su Disposición Final Quinta contenía ya un mandato dirigido al Gobierno para el establecimiento de las condiciones básicas de accesibilidad y no discriminación que debían reunir los entornos, productos y servicios necesarios para la participación de las personas con discapacidad en la vida política y en los procesos electorales ${ }^{40}$.

A pesar de que se aprobaron diversas normas sobre los derechos de participación política de personas con discapacidad, sin embargo, hubo que esperar hasta la aprobación del Real Decreto 422/20II, de 25 de marzo, por el que se aprueba el Reglamento sobre las condiciones básicas para la participación de las personas con discapacidad en la vida política y en los procesos electorales, para que la normativa española regulara de manera más completa los derechos de participación de las personas con discapacidad, aunque aún principalmente

40. En línea con este mandato, posteriormente, se aprobaron varias normas, como la Ley Orgánica 9/2007, de 8 de octubre, de modificación de la Ley Orgánica 5/I985, de I9 de junio, del Régimen Electoral General, el Real Decreto I6I2/2007, de 7 de diciembre, por el que se regula el procedimiento de voto accesible que facilita a las personas con discapacidad visual el ejercicio del derecho de sufragio, y la Ley $27 / 2007$, de 23 de octubre, por la que se reconocen las lenguas de signos españolas y se regulan los medios de apoyo a la comunicación oral de las personas sordas, con discapacidad auditiva y sordo ciegas, que también hacían referencia a la accesibilidad y la participación política de dichas personas. enfocada -como la normativa precedente- a mejorar las condiciones de accesibilidad física.

Esta norma de 20 I I ya sería aprobada después de la entrada en vigor en 2008 de la Convención sobre los Derechos de las Personas con Discapacidad. El nuevo enfoque basado en los derechos humanos de que hacía gala la Convención iba a exigir una readaptación y adecuación del marco legal español al flamante tratado internacional, lo que se materializó en 20I I con la aprobación de la Ley 26/20II, de I de agosto, de adaptación normativa a la Convención Internacional sobre los Derechos de las Personas con Discapacidad, que recogió el marco legal de los derechos de las personas con discapacidad en cierta consonancia con los términos establecidos en la Convención, y que en materia de derechos políticos también conllevó ciertas modificaciones legales de la LIONDAU, sobre todo, nuevamente, en lo que respecta a la accesibilidad física de las personas con discapacidad.

En la actualidad, el marco legal general de los derechos de las personas con discapacidad queda enmarcado en el Real Decreto-Legislativo I/20I3, de 29 de noviembre, por el que se aprueba el Texto Refundido de la Ley General de derechos de las personas con discapacidad y de su inclusión social (BOE de 3 de diciembre de 2013). Esta Ley incluye como derechos de las personas con discapacidad en los artículos 53 y 54 el derecho de participación en la vida política y pública "en igualdad de condiciones que el resto de ciudadanos conforme a la normativa en vigor"; no obstante, esta regulación viene a sostener y apoyar las restricciones al derecho de voto de las personas con discapacidad que aún hoy existen desde la Ley de Régimen Electoral de I985.

Como balance en el plano nacional, podemos afirmar que la normativa interna ha experimentado avances sustanciales en lo que se atiene a la mejora de las condiciones de accesibilidad de las personas con discapacidad, sobre todo, de aquéllas que tienen una discapacidad física, pero sigue siendo precaria en lo que respecta a otros tipos de discapacidades, como son la psíquica o intelectual. 
De igual modo, resulta fundamental analizar el desarrollo jurisprudencial que, en el plano nacional, ha experimentado el derecho de voto de las personas con discapacidad tras la ratificación por parte de España de la Convención de 2006. Sin duda, guiados por la labor del Tribunal Europeo de Derechos Humanos, y superando ampliamente el enfoque todavía restrictivo de nuestro legislador, los tribunales españoles están abriendo camino -si bien no de manera generalizada- para un desarrollo más adecuado y un efectivo cumplimiento del derecho de voto de las personas con discapacidad, en especial de aquéllas con discapacidad psíquica o intelectual. Entre las sentencias más sobresalientes de esta innovadora tendencia jurisprudencial, debemos destacar la Sentencia de la Audiencia Provincial de Ciudad Real, de 24 de octubre de 20I2, la cual, en base al artículo 23 de la Constitución Española, y el valor interpretativo del artículo ro.2 de la CEı978, establece como principio general "el derecho de toda persona discapacitada a participar en la vida política de un Estado", teniendo como base el siguiente argumento:

\section{“[...] El desconocimiento completo del sistema político español no puede suponer la pérdida del derecho de voto a una persona [...] pues lo esencial es la capacidad para decidir, elegir u optar libremente y sin influencias externas en un determinado proceso electoral [...] dicho ejercicio sólo requiere una manifestación de voluntad".}

En esta línea, también encontramos la Sentencia de la Audiencia Provincial de Barcelona, de I $3_{3}$ de marzo de $2014^{4 \mathrm{I}}$, que únicamente permite la privación del derecho de sufragio a una persona con discapacidad "cuando haya una prueba directa y concluyente de que, en el determinado momento de la votación, el discapacitado estará privado de toda razón y de todo sentido". En consonancia con ello, la sentencia del mismo tribunal, de 5 de marzo de

4I En esta misma línea jurisprudencia, $c f r$. Sentencias de la Audiencia Provincial de Barcelona de ro de noviembre de 20I4, I9 de noviembre de 20I4 y I 8 de marzo de 2015.
2015 , restablece el derecho de voto a una persona con discapacidad mental grave y un grado de discapacidad del $73 \%$, con "una muy limitada capacidad intelectiva y cognitiva", teniendo como argumento central que "la disminución de las facultades cognitivas o volitivas no equivalen a su ausencia, no quedando probado que la demandada tenga alterada la percepción de la realidad o perturbada su capacidad de decisión autónoma hasta el punto de no saber qué es votar" (Martínez- Pujalte, 20 I 5: 94). En esta misma línea abundan las recientes sentencias también dictadas por la Audiencia Provincial de Barcelona de 27 de mayo y de I 2 de julio de 20I6; de especial relevancia resulta la de 27 de mayo la cual, tras un extenso desarrollo de las normas convencionales y recomendaciones de diversas instancias internacionales a favor del reconocimiento del derecho de sufragio a las personas con discapacidad, incide en un aspecto esencial: "el derecho de participación política no puede sufrir discriminación alguna por razón de enfermedad mental, ni puede un juez establecer un estándar de exigibilidad de capacidades cognitivas o intelectivas superiores a las que sean predicables en cualquier ciudadano para impedir el ejercicio del derecho de voto, de manera que sólo razones muy específicas, motivadas y justificadas en el interés del presunto incapaz o en razones de orden público pueden legitimar una limitación del derecho de sufragio activo.[..]”.

Por ende -prosigue la sentencia-, solo podrá declararse judicialmente la incapacidad para votar "cuando se acredite que el demandado no puede ejercer ese derecho fundamental y personalísimo con efectos jurídicos, por ir en perjuicio del propio incapaz o cuando haya una prueba directa y concluyente de que, en el determinado momento de la votación, el discapacitado estará privado de toda razón y de todo sentido".

Sin embargo, esta esperanzadora línea jurisprudencial aún no constituye la tendencia generalizada entre nuestros tribunales. En la mayoría de los casos se siguen dictando por nuestros tribunales sentencias estandarizadas de incapacitación que conllevan aparejadas, sin fundamentación separada e individualizada, 
la privación del derecho de sufragio de estas personas declaradas incapaces. En la casi totalidad de las sentencias de incapacitación, las restricciones al derecho de voto de las personas con discapacidad y, en concreto, a las personas con discapacidad intelectual o psíquica, siguen aún hoy manteniendo como base la cláusula de estilo (Díaz Alabart, 20I2: I4-I 5 ) que constituye el artículo 3 de la Ley Orgánica del Régimen Electoral General (LOREG).

En lo que concierne a la doctrina del Tribunal Supremo, si bien existen sentencias que desarrollan una línea positiva para el derecho de sufragio de las personas con discapacidad, como la sentencia número 34I/20I4, de I de julio, que afirma que serán causas de incapacitación aquellas que impiden en la realidad el autogobierno $\mathrm{O}^{42}$ de una persona determinada ${ }^{43}$, recientes sentencias como la de $\mathrm{I} 7$ de marzo o la de 3 de junio de 2016 constituyen precedentes negativos, que mantienen que la privación del derecho de sufragio a las personas con discapacidad es legalmente posible y compatible con la Convención de Nueva York, si la medida sirve para proteger los intereses del incapaz y el propio interés general de que la participación electoral se realice de forma libre y "con un nivel de conocimiento mínimo respecto del hecho de votar " y de la decisión adoptada. A nuestro juicio, tal y como está formulada en estas dos resoluciones, esta doctrina se opone a las normas internacionales habida cuenta que ampara la discriminación hacia las personas con discapacidad en relación al ejercicio del derecho de sufragio al admitir la exigencia a las personas con discapacidad de

42. La propia sentencia define el "autogobierno" como la aptitud necesaria para obrar por uno mismo, para actuar libremente.

43. En esta sentencia, además, el Alto Tribunal defiende la compatibilidad de la incapacitación y la reserva al incapaz de su derecho de sufragio, pues una cosa es que una persona no pueda regirse por sí misma, ni administrar su patrimonio, y otra distinta que esté impedida para ejercitar correctamente el derecho de sufragio; asimismo, en la resolución, el Tribunal desarrolla el concepto (ya introducido en los albores de vigencia de la Convención por la STS de 29 de septiembre de 2009) del "traje a medida" para la graduación individualizada de la incapacidad en cada caso, pues "la incapacitación ha de adaptarse a la concreta necesidad de protección de la persona afectada por la incapacidad [...]”. un conocimiento mínimo respecto del hecho de votar y de la decisión que se adopte, lo que sin embargo no se requiere a las personas $\sin$ discapacidad. No obstante, como expondremos en el apartado de conclusiones, este enfoque podría ser corregido y validado si en lugar de requerir un nivel de conocimiento mínimo sobre el hecho de votar -lo que establecería una regla que serviría para excluir a un número elevado de personas con discapacidad psíquica o intelectual- se sustituyera por un enfoque contrapuesto marcado por la excepcionalidad: es decir, la sola posibilidad de privar del derecho de sufragio activo tras un examen individualizado, única y exclusivamente, a las personas con una "absoluta falta de discernimiento y comprensión sobre el acto de votar”, en consonancia con la positiva línea jurisprudencial descrita en el párrafo precedente.

La consecuencia fáctica de nuestra legislación actual y de la aún mayoritaria práctica judicial de desposeer del derecho de sufragio de manera automática a toda persona declarada incapaz radica en que cerca de I00.000 personas con discapacidad psíquica e intelectual en España están privadas de su derecho de voto, en virtud de sentencias judiciales de incapacitación civil ${ }^{44}$, a pesar de que existe una Convención internacional vinculante, la CDPD, en vigor en España desde 2008, que obliga a nuestras autoridades a reconocer y tomar las medidas necesarias para que todas las personas con discapacidad -sin distinción alguna- puedan ejercer su derecho al voto en los mismos términos que el resto de personas sin discapacidad.

Como prueba de que existen otros modelos nacionales que constituyen una acogida más adecuada de la Convención de Nueva York, es necesario poner de relieve que la recepción de la CDPD -en lo que concierne al artículo 29 en conexión con el artículo I 2- ha sido más profunda y positiva en otros países de nuestro entorno. En este sentido, según información de la Agencia de la Unión Europea para los Derechos Humanos, en su informe de $2014^{45}$,

44. Según datos de 2016 de la Junta Electoral Central. 45. Agencia de la Unión Europea para los Derechos 
siete de los 28 Estados miembros de la UE -Austria, Croacia, Italia, Letonia, Países Bajos, Suecia y el Reino Unido- garantizan el derecho de voto para todas las personas con discapacidad, incluyendo a aquellas que no tienen reconocida su capacidad jurídica por los ordenamientos nacionales ${ }^{46}$. En concreto, en Croacia, la reforma legal de $20 \mathrm{I} 2$ abolió la exclusión del derecho de voto de las personas sin capacidad jurídica, por lo que las personas privadas de capacidad jurídica pudieron participar en las elecciones al Parlamento Europeo y las elecciones locales de 2013. De modo similar, las reformas del Código Civil de Letonia -que entraron en vigor en 20I3pusieron fin a la negación del derecho de voto para los privados de capacidad jurídica.

En definitiva, en lo que concierne al derecho de participación política de las personas con discapacidad, parece indudable que los Estados -como los siete europeos antes citados- que garantizan el derecho de voto para todas las personas con discapacidad, incluyendo a aquellas que no tienen reconocida su capacidad jurídica por los ordenamientos nacionales, son los que cumplen más correctamente con el mandato convencional del artículo 29 de la CDPD, los que no recibirán resoluciones condenatorias -sobre este derecho- en los tribunales internacionales estudiados ni serán censurados en las observaciones finales emitidas tras el examen del Comité sobre los Derechos de las Personas con Discapacidad.

Fundamentales (20I4): El derecho a la participación política para las personas con discapacidad: indicadores de derechos humanos, Luxemburgo: Agencia de la Unión Europea para los Derechos Fundamentales.

46. España sigue ubicada en un segundo grupo de países, entre los cuales se encuentran también Hungría y Eslovenia, en los que se evalúa de manera individualizada la capacidad de las personas para ejercer su derecho al voto denegándolo en un gran número de casos. En el extremo opuesto, tenemos, por último, un tercer grupo de países de la UE, que prohíben votar a las personas con discapacidad que han sido desprovistas de su capacidad jurídica, entre ellos, Bélgica, Alemania, Polonia o Portugal. Por su parte, Francia formuló una declaración interpretativa al artículo I 2 de la CDPD, consistente en que su aplicación se realizaría de conformidad con su legislación nacional, lo que le permite restricciones al derecho de voto de las personas con discapacidad que han sido privadas de su capacidad jurídica.

\section{Conclusiones}

Como conclusión de nuestro trabajo, debemos sostener que la LOREG debe ser reformada para adecuarla al tenor, finalidad y espíritu del artículo 29 (en conexión con el art. I2) de la Convención sobre los Derechos de las Personas con Discapacidad, con objeto de que España ponga fin al incumplimiento de un tratado internacional plenamente obligatorio. La reforma que se propone de este precepto consistiría en reconocer, con arreglo al artículo 29 -en conexión con el artículo I 2- de la Convención sobre los Derechos de las Personas con Discapacidad, el derecho de voto de todas las personas con cualquier tipo de discapacidad, en igualdad de condiciones que las demás, y sin discriminación, eliminando, en consecuencia, toda restricción al derecho de voto de las personas con discapacidad, lo que habría de conducir en definitiva a la derogación del artículo 3 de la LOREG.

No obstante lo anterior, frente a esta propuesta de máximos se alzan principios de derecho internacional como la soberanía de los Estados, y normas y resoluciones internacionales, como el artículo 25 PIDCP, y la propia jurisprudencia del TEDH (que, como se ha examinado, estrecha el "margen de apreciación estatal" respecto a la razonabilidad de las restricciones al ejercicio del derecho de voto de las personas con discapacidad, pero, sin embargo, -hay que decirlo- no elimina de forma categórica esta facultad de los Estados) y, por último, abundante normativa y jurisprudencia nacional que con gran frecuencia restringe este derecho de sufragio a estas personas por temor a los posibles abusos y suplantación de su personalidad (Gálvez Muñoz, 2009: 82-86). Por tal motivo, como propuesta alternativa, sugerimos una reforma del artículo 3 de la LOREG que -creemos- puede cohonestar con estos principios, normas y resoluciones judiciales.

Esta reforma alternativa radicaría en que la restricción al ejercicio de sufragio únicamente podría basarse en la falta absoluta de todo 
discernimiento y comprensión sobre el acto de votar; es decir, la restricción no se basaría en la discapacidad -lo que está vetado por la CDPD-, sino que respetaría el principio de "igualdad" y "no discriminación", dado que esta "falta absoluta de discernimiento y comprensión sobre el acto de votar" se aplicaría a toda persona, y no sólo a las personas con discapacidad psíquica o intelectual. Huelga decir que dicha privación del derecho de sufragio sólo podría adoptarse con carácter restrictivo y excepcional por una decisión judicial concreta, tras un examen individualizado de la persona, y con un pronunciamiento específico relativo al derecho de sufragio activo. Como apuntamos, esta propuesta sería coherente con la línea jurisprudencial más próxima a un correcto cumplimiento de la CDPD, iniciada en España por la Sentencia de la Audiencia Provincial de Ciudad Real, de 24 de octubre de 20 I 2 y seguida y desarrollada, entre otras, por las vanguardistas sentencias de la Audiencia Provincial de Barcelona de $\mathrm{I} 3$ de marzo de 20I4, 5 de marzo de 20I 5, 27 de mayo y de I 2 de julio de 2016 , que -como hemos analizado en el apartado 4- confirman el derecho de voto de las personas con discapacidad psíquica o intelectual, y solo permiten la restricción de este derecho "cuando haya una prueba directa y concluyente de que, en el determinado momento de la votación, el discapacitado estará privado de toda razón y de todo sentido" (MartínezPujalte, 201 5: 94), es decir, cuando la persona no pueda manifestar su voluntad ni tomar decisiones propias, ni autónomamente ni con apoyos, sobre el acto de votar. En definitiva, en términos de Presno Linera, cuando no presente una mínima capacidad de "autodeterminación política” (Presno Linera, 2002: 522-532).

Sentado lo anterior, debemos finalizar destacando que la situación normativa actual, que gira en torno al artículo 3 de la LOREG, mantiene la negación de este derecho fundamental a las personas con discapacidad, en especial, a las personas con discapacidad psíquica o intelectual, y constituye una barrera difícilmente salvable para el goce pleno del resto de derechos que establece la Convención sobre los Derechos de las Personas con Discapacidad (López Medel, 20I 5). Este reconocimiento del derecho de voto de las personas con discapacidad en igualdad de condiciones que el resto de ciudadanos, implicaría el pleno empoderamiento de estas personas, lo que les capacitaría para exigir con mayor peso e influencia sus derechos ante las administraciones públicas y las autoridades políticas.

En suma, si el Estado español materializara, de una vez por todas, la derogación del artículo 3 de la LOREG o, al menos, llevara a cabo la reforma del citado precepto en los términos propuestos subsidiariamente, ello significaría que España cumpliría más adecuadamente con el derecho internacional y que habría dado un paso necesario para hacer efectivos los derechos de todas las personas con discapacidad, así como, en definitiva, para posicionar a nuestro país entre las democracias más avanzadas e inclusivas. 
Andrés Sáenz de Santa María, P. (20I4): Sistema de derecho internacional público, Pamplona: Ed. Civitas.

Bariffi, F.J. (2015): El régimen jurídico internacional de la capacidad jurídica de las personas con discapacidad, Madrid: Dykinson.

Boussuyt, M. J. (I987): Guide to the 'Travaux Préparatoires' of the International Covenant on Civil and Political Rights, Leiden: Martinus Nijhoff Publishers.

Brems, E. (200I): Human rights. Universality and Diversity, The Hague: Kluwer Law International.

Castro-Rial Garrone, F. (1998): “La Declaración Universal como elemento básico del orden internacional”, en Balado, M. y García, J. A. (dir.): La Declaración Universal de los Derechos Humanos en su 50 aniversario. Barcelona: Bosch.

Comisión Europea (2007): Compendium of International Standards for elections, Bruselas: Comisión Europea.

Cuenca Gómez, P. (20I2): "La incidencia del derecho internacional de los derechos humanos en el derecho interno: la interpretación del artículo I0.2 de la Constitución Española”. Revista de Estudios Jurídicos, I2: I-24.

Dalla Via, A. R. (20I I): “Derechos políticos, normativa electoral y equidad en los procesos electorales". Cuaderno de Capel, 57: 25-6I.

De La Rasilla, I. (I998): “El derecho a la participación política en la Declaración Universal de Derechos Humanos de I948. Una breve introducción a su consideración como norma consuetudinaria 'in statu nascendi', en Escobar, C. (dir.): Los derechos humanos en la sociedad internacional del siglo XXI. Madrid: Escuela diplomática.

Díaz Alabart, S. (2OI2): "El derecho al sufragio activo de las personas con discapacidad. La visión civilista”. Revista de Derecho Privado, 96: 3-24.
Díez de Velasco, M. (2013): Instituciones de derecho internacional público, Madrid: Tecnos.

España. Ley 26/20I I, de I de agosto, de adaptación normativa a la Convención Internacional sobre los Derechos de las Personas con Discapacidad, Boletín Oficial del Estado, 2 de agosto de 20 I I, núm. I 84, pp. 87478-87494.

España. Ley 27/2007, de 23 de octubre, por la que se reconocen las lenguas de signos españolas y se regulan los medios de apoyo a la comunicación oral de las personas sordas, con discapacidad auditiva y sordo ciegas, que también hacían referencia a la accesibilidad y la participación política de dichas personas, Boletín Oficial del Estado, 24 de octubre de 2007, núm. 255, pp. 4325 I-43259.

España. Ley 51/2003, de 2 de diciembre, de igualdad de oportunidades, no discriminación y accesibilidad universal de las personas con discapacidad, Boletín Oficial del Estado, 3 de diciembre de 2003, núm. 289, pp. 4318743195 .

España. Ley Orgánica 5/I985, de I9 de junio, del Régimen Electoral General, Boletín Oficial del Estado, 20 de junio de I985, núm. I47, pp. I9IIO-I9I 34 .

España. Ley Orgánica 9/2007, de 8 de octubre, de modificación de la Ley Orgánica 5/1985, de I9 de junio, del Régimen Electoral General, Boletín Oficial del Estado, 9 de octubre de 2007, núm. 242, pp. 40968-40969.

España. Real Decreto 422/20I I, de 25 de marzo, por el que se aprueba el Reglamento sobre las condiciones básicas para la participación de las personas con discapacidad en la vida política y en los procesos electorales, Boletín Oficial del Estado, 30 de marzo de 20 I I, núm. 76, pp. 3304I-33046.

España. Real Decreto I6I2/2007, de 7 de diciembre, por el que se regula el procedimiento de voto accesible que facilita a las personas 
con discapacidad visual el ejercicio del derecho de sufragio, Boletín Oficial del Estado, 8 de diciembre de 2007, núm. 294, pp. 5061550617 .

España. Real Decreto Legislativo I/20I3, de 29 de noviembre, por el que se aprueba el Texto Refundido de la Ley General de derechos de las personas con discapacidad y de su inclusión social, Boletín Oficial del Estado, 3 de diciembre de 2013, núm. 289, pp. $95635^{-}$ 95673 .

Gálvez Muñoz, L. A. (2009): El derecho de los discapacitados y otras personas vulnerables. Teoría, crítica y práctica, Valencia: Tirant lo Blanch.

Goldman, H. et al. (I98I): "Defining and counting the chronically mentally ill”. Hospital and Community Psychiatry, 32 (I): 2 I-27.

González Volio, L. (2005): "Los pueblos indígenas y el ejercicio de los derechos políticos de acuerdo a la Convención Americana: el Caso Yatama contra Nicaragua", Revista IIDH, 4I: 3I 7-345.

Hartmann, C. (2003), Towards Internalisation of Democracy?, Bochum: Institute of Development Research.

Instituto de Derechos Humanos Bartolomé de las Casas (2008): La Convención Internacional sobre los Derechos de las Personas con Discapacidad y su impacto en el ordenamiento jurídico español, Madrid: IDHBC.

Jarillo Aldenueva, A. (2006): El derecho de participación política y la democracia en el ordenamiento internacional: análisis desde la perspectiva europea, Madrid: UNED.

Jarillo Aldenueva, A. (20I2): Pueblos y democracia en derecho internacional, Valencia: Tirant lo Blanch.

López- Medel Báscones, J. (201 5): ¿Es compatible la democracia con la privación de miles de votos a ciudadanos discapacitados? (en línea). $<$ http://www.abogacia.es/201 5/02/2 5/escompatible-la-democracia-con-la-privacion-demiles-de-votos-a-ciudadanos-discapacitados/>
Martínez- Pujalte, A. L. (20I 5): Derechos fundamentales y discapacidad, Madrid: Cinca.

Organización Mundial de la Salud (200I): Clasificación Internacional del Funcionamiento, de la Discapacidad y de la Salud (CIF). Madrid: Ministerio de Trabajo y Asuntos Sociales.

Pérez Alberdi, M. R. (20I3): "La delimitación del derecho de sufragio activo por el Tribunal Europeo de Derechos Humanos". Revista de Derecho Político, 88: 337-367.

Pérez Bueno, L. C. (2008): “La recepción de la convención de la ONU en el ordenamiento jurídico español: ajustes necesarios”. Siglo Cero: Revista Española sobre Discapacidad Intelectual, 228 (39): 62-7I.

Pérez Luño, A. E. (2003): Derechos humanos, Estado de Derecho y Constitución, Madrid: Tecnos.

Presno Linera, M. A. (2002): "La titularidad del derecho de participación política". Boletín Mexicano de Derecho Comparado, I04: 5 I7$55^{8}$.

Sánchez- Molina, P. (2014): "El margen de apreciación nacional en las sentencias del Tribunal Europeo de Derechos Humanos relativa al derecho a elecciones libres". Estudios de Deusto, 62 (I): 37I-386.

Sanjosé Gil, A. (2007a), "El primer tratado de derechos humanos del siglo XXI: La Convención sobre los Derechos de las Personas con Discapacidad". REEI, I3.

Sanjosé Gil, A. (2007b): "Situación del Proyecto de Convenio de las Naciones Unidas sobre los Derechos de las Personas con Discapacidad" en Fernández Liesa, C. (dir.): La protección internacional de las personas con discapacidad. Madrid: Universidad Carlos III de Madrid.

Schalock, R. L. et al. (2010): Intellectual disability: definition, classification, and systems of supports, Washington, D.C.: American Association on Intellectual and Developmental Disabilities. 